\title{
REGISTROS PALINOLÓGICOS E MUDANÇAS AMBIENTAIS DURANTE O HOLOCENO DE TAQUARUSSU (MS)
}

\author{
MAURO PAROLIN \\ Programa de Pós-Graduação em Ecologia de Ambientes Aquáticos Continentais, UEM, Rua Chafic B. Maluf, 21, 87300-170, Campo \\ Mourão, PR, Brasil.mauroparolin@gmail.com \\ SVETLANA MEDEANIC \\ Universidade Federal do Rio Grande do Sul, Av. Bento Gonçalves, 9500, 91509-900, Porto Alegre, RS, Brasil. \\ svetlana.medeanic@ufrgs.br \\ JOSÉ CÂNDIDO STEVAUX \\ Universidade Guarulhos, Pça. Tereza Cristina, 01,07023-070, Guarulhos, SP, Brasil.jcstevaux@uem.br
}

\begin{abstract}
RESUMO - Foi analisado o material palinológico de 15 amostras de turfa obtidas em três perfurações com “vibro-core” na região de Taquarussu, MS (22³0'S, $\left.52^{\circ} 20^{\prime} \mathrm{W}\right)$. Quatro datações pelo método do ${ }^{14} \mathrm{C}$ obtiveram os seguintes resultados: $11.570 \pm 80$ anos AP (240 $\mathrm{cm}$ profundidade), $9.710 \pm 80$ anos AP ( $220 \mathrm{~cm}$ profundidade), $4.610 \pm 70$ anos AP (130 cm profundidade) e 4.010 \pm 80 anos AP (29-35 cm profundidade). Os palinomorfos foram representados por grãos de pólen e esporos de plantas terrestres e aquáticas, zigosporos e colônias de algas. Em algumas amostras foi observado grande número de partículas de carvão. Foram determinadas seis palinozonas correspondentes a seis etapas de desenvolvimento paleoambiental. As etapas mais antigas (palinozonas I-IV) são caracterizadas por gramíneas, com predominância de um clima seco continental. As etapas mais recentes (palinozonas V-VI) são caracterizadas pelo aumento progressivo da umidade. A freqüência significante de partículas de carvão nas amostras está provavelmente correlacionada a incêndios. Os dados obtidos indicaram oscilações climáticas notáveis durante o Holoceno: clima seco e relativamente continental durante o Holoceno Inferior e Médio e mais úmido desde o Holoceno Tardio até o presente.
\end{abstract}

Palavras chave: palinologia, paleoclima, turfa, Taquarussu, Holoceno.

ABSTRACT - PALYNOLOGICAL RECORDS AND ENVIRONMENTAL CHANGES DURING THE HOLOCENE OF THE TAQUARUSSU REGION, MS. A palynological study was made based on 15 peat samples obtained from three vibro-cores in Taquarussu region (Mato Grosso do Sul, Brazil ; $22^{\circ} 30^{\prime} \mathrm{S}, 52^{\circ} 20^{\prime} \mathrm{W}$ ). Four samples were dated by ${ }^{14} \mathrm{C}$ method: $11.570 \pm 80$ years BP $(240 \mathrm{~cm}$ depth $), 9.710 \pm 80$ years BP $(220 \mathrm{~cm}$ depth), $4.610 \pm 70$ years BP (130 cm depth) and 4.010 \pm 80 years BP (29-35 cm depth). The palynomorphs were represented by pollen grains and spores of higher terrestrial and aquatic plants, zygospores and colonies of chlorophycean and zygnematophycean algae. In some samples, a great number of charcoal particles were observed. Based on palynological data, six palynozones were characterized, which correspond to six stages of palaeoenvironment development. The earlier stages (palynozones I-IV) are characterized by wide spreading of grassland (Poaceae predominant), under dry and continental climate. The younger stages (palynozones V-VI) are characterized by progressive increase in humidity. The significant frequency of charcoal particles in the samples may be connected to burning. Obtained data indicate notable climatic oscillations during the Holocene: dryer and relatively continental climate during the Early and Middle Holocene, and more humid since the Late Holocene till the present.

Key words: Palynology, palaeoclimatology, peat, Taquarussu, Holocene.

\section{INTRODUÇÃO}

A região de Taquarussu (MS), segundo estudos de Campos \& Souza (1997), é caracterizada pela transição entre a floresta estacional semidecidual submontana e a savana (cerrado), compreendendo uma área já bastante alterada, ocupada por campos artificiais ou pastagens. Os sedimentos holocenos são representados por depósitos predominantemente arenosos de origem fluvial e eólica (Parolin \& Stevaux, 2001) e turfeiras localizadas nas margens do rio Esperança. O conhecimento da história quaternária desta área, sujeita atualmente ao impacto antrópico intensivo, é muito 
importante para avaliar o grau de mudanças ambientais naturais e as transformações causadas pelo homem, bem como estimar as áreas da distribuição de mata ciliar no passado e sua conexão com mudanças climáticas.

A ocorrência de um período de clima mais seco que o atual no Holoceno em diferentes localidades do Centro-Sul do Brasil foi identificada por vários autores (Barbosa et al., 1990; Van der Hammen, 1991; Thomas \& Thorp, 1995; Ledru, 1993; Ledru et al., 1996; Stevaux, 2000, entre outros). Na região do alto rio Paraná, esse período mais seco foi informado por Jabur (1992) e Stevaux (1993, 1994a, 1994b e 2000). Nesses trabalhos, constatou-se que a região passou por um período mais seco entre 3.500 a 1.500 anos AP, seguido por um período mais úmido a partir dos 1.500 anos AP. Iriondo \& Kröhling (1995) e Iriondo et al. (1997) indicaram que a região nordeste da Argentina teria sofrido um processo de ressedimentação e remobilização de materiais pela influência do loess pampeano, que teria se formado antes do Holoceno, mas que, provavelmente, teve períodos de reativação durante o Holoceno, principalmente nas fases de clima mais seco. Stevaux \& Santos (1998) discutem a possibilidade de que esse mesmo processo tenha agido na região de Taquarussu. Pesquisas recentes, elaboradas por Kramer \& Stevaux (1999), Stevaux (2000), e Parolin \& Stevaux (2001) na região de Taquarussu (MS) estabeleceram um hiato temporal de aproximadamente 9 mil anos (definido entre 3 e 12.000 anos AP) com intensa atividade eólica por volta de 3.000 anos AP.

Segundo Thomas \& Thorp (1995), as condições de aridez do Último Máximo Glacial variaram de região para região e, após 22.000 anos AP, esse período mais seco aparece na maioria das regiões estudadas. A transição PleistocenoHoloceno é indicada por um período instável nas condições de umidade que começaram em torno de 12.500 anos AP e no Holoceno, isto devido à abundância de dados após 10.000 anos AP. Corroboram com esses dados os estudos de mudanças globais do Quaternário na América do Sul efetuados por Coltrinari (1993), que relatou uma distribuição heterogênea das evidências paleoambientais nos cinturões andinos e nas paisagens tropicais das partes leste e central do continente.

Stevaux \& Santos (1998), com base em datações de ${ }^{14} \mathrm{C}$, postularam uma mudança extrema na hidrologia do rio Paraná em torno de 8.000 anos AP. Segundo esses autores, essa mudança provocou a incisão vertical do canal e a conseqüente formação de um terraço de cerca de $10 \mathrm{~m}$ de altura (Terraço Fazenda Boa Vista), posicionando o início da construção da atual planície de inundação desse rio por volta de 6.000 anos AP.

Nas áreas adjacentes, os primeiros dados palinológicos realizados na planície de inundação do alto rio Paraná registraram um período mais seco do que o atual encerrado há, pelo menos, 1.700 anos AP (Barczyczyn, 2001, Barczyczyn et al., 2001, Medeanic \& Stevaux, 2003). Estes trabalhos, contudo, basearam-se em análises palinológicas e datações de idade absoluta que permitiram aos autores interpretações de caráter generalizado. $\mathrm{O}$ presente trabalho mostra os primeiros resultados palinológicos obtidos em amostras de uma turfeira holocena situada na região de Taquarussu, Estado de Mato Grosso do Sul. Os estudos palinológicos possibilitaram as reconstruções paleoambientais e paleoclimáticas sugerindo condições de clima seco durante o Holoceno Inferior e Médio e clima mais úmido durante o Holoceno Tardio.

\section{ÁREA DE ESTUDO}

A área de estudo está situada próxima à margem direita do alto curso do rio Paraná, no município de Taquarussu, sudeste do Estado de Mato Grosso do Sul, e faz parte da Unidade Geomorfológica Fazenda Boa Vista (Figura 1). Segundo Stevaux (1993), esta unidade é um terraço escavado em-depósitos antigos do rio Paraná (31.400 1.700 e $42.500 \pm$ 1.700 anos AP para a base dos depósitos). Stevaux (1993) subdividiu a Unidade Fazenda Boa Vista em três subunidades: (i) Unidade Fazenda Boa Vista Leque - onde a superfície apresenta-se parcialmente recoberta por pequenos leques aluviais inativos; (ii) Unidade Fazenda Boa Vista Baixa composta por uma série de cicatrizes de um antigo sistema de canais fluviais pouco desenvolvidos; e (iii) Unidade Fazenda Boa Vista Alta - definida por uma faixa de 200 a $2.000 \mathrm{~m}$ de largura desenvolvida ao longo do limite com a planície de inundação do rio Paraná, recoberta por pequenas colinas arenosas interpretadas como um antigo campo de dunas dissipadas (Parolin \& Stevaux, 2001). Santos \& Stevaux (2000) sugeriram que os depósitos da Unidade Fazenda Boa Vista tenham sido formados pelo próprio rio Paraná, em sistema primeiramente bastante energético e com descargas concentradas do tipo entrelaçado (porção basal correspondente ao cascalho), passando a um sistema entrelaçado de menor energia (porção arenosa superior). Estudos realizados por Jabur (1992), Stevaux (1993, 1994a, 1994b) e Stevaux et al. (1997), na planície de inundação do rio Paraná e em alguns de seus tributários, na região de Porto Rico (PR), forneceram dados suficientes para os primeiros esboços da caracterização paleoclimática daquela região, indicando, pelo menos, quatro eventos sendo: (i) seco - no Pleistoceno Tardio, iniciado em cerca de 40.000 anos AP; (ii) úmido - no Holoceno Médio entre 3.500 e 7.500 anos AP; (iii) seco - no Holoceno Tardio, entre 3.500 a 1.500 anos AP; e (iv) evento úmido desde 1.500 anos AP até o presente.

A região apresenta-se atualmente com clima tropical úmido, temperatura média anual de $24^{\circ} \mathrm{C}$ e regime pluviométrico entre 1.250 e $1.500 \mathrm{~mm} / \mathrm{ano}$. Segundo Nimer (1989), essas precipitações não são bem distribuídas ao longo do ano, seu regime sazonal é tipicamente tropical, com acentuada máxima no verão e mínima no inverno.

De acordo com Souza et al. (2004), dentre os vários tipos de formação vegetal que compõem o sistema dos rios Baia e Ivinhema, na região dos terraços, encontram-se a floresta estacional semidecidual submontana, floresta ciliar, floresta de brejo e buritizal. A região de estudo, segundo Campos \& Souza (1997), situa-se na transição entre floresta estacional semidecidual submontana e savana (cerrado), que no passado foi coberta por florestas e hoje se apresentam com 


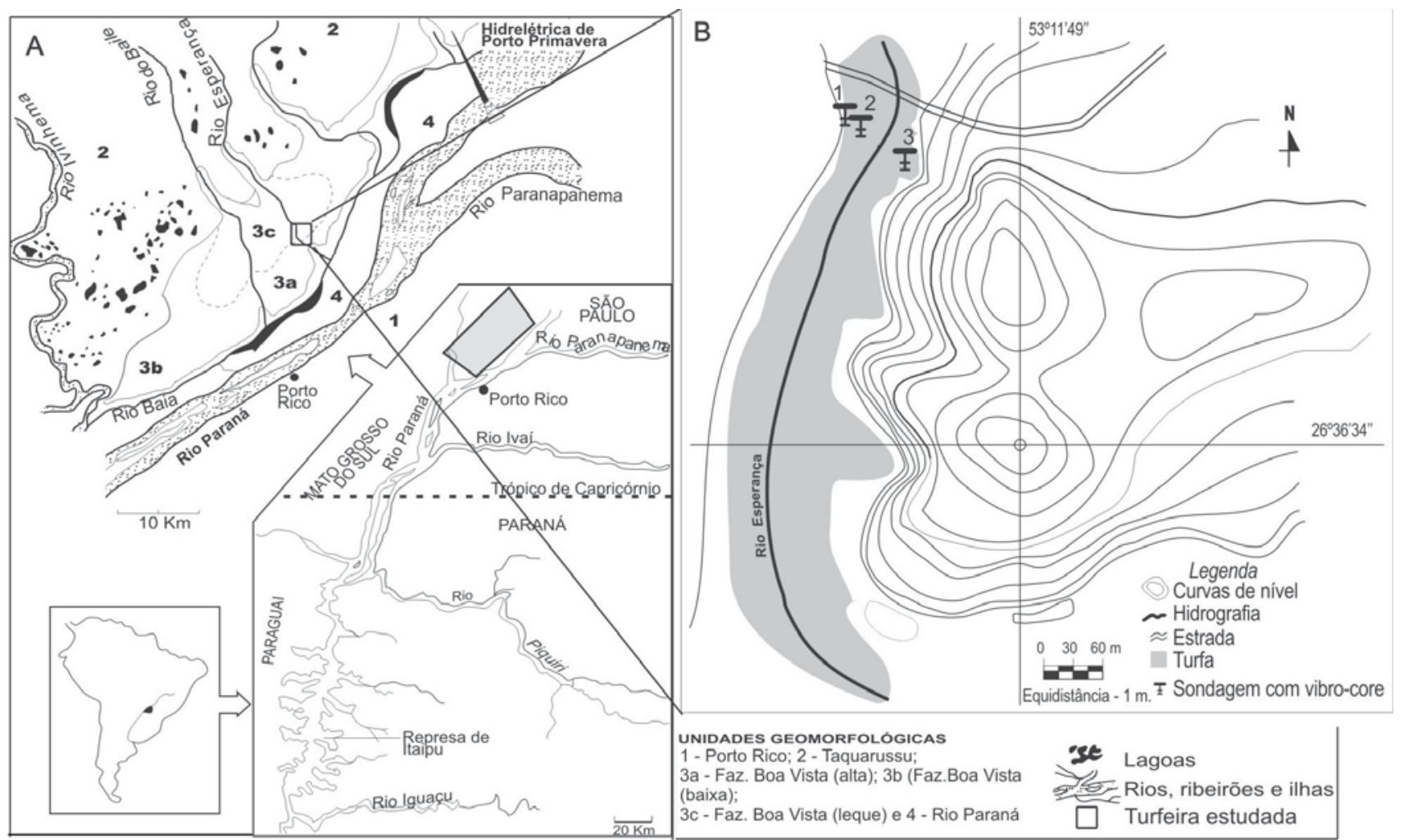

Figura 1. Localização da área de estudo. A, mapa com unidades geomorfológicas; B, detalhe topográfico de uma paleoduna com a localização das sondagens com vibro-core, (modificado de Parolin \& Stevaux, 2001 e Stevaux, 1993).

Figure 1. Location map of study area. A, map with geomorphological units; B, topographic detail of a paleodune with the location of the cores (modified from Parolin \& Stevaux, 2001 e Stevaux, 1993).

intensa ação antrópica, com evidente predomínio de gramíneas forrageiras e algumas invasoras, além de alguns indivíduos arbóreos que podem ocorrer isoladamente. Campos \& Souza (1997), mediante observações locais, sugerem que a savana preexistiu à vegetação típica florestal e ainda permanece apenas naqueles ambientes onde as espécies típicas da floresta não desenvolveram adaptações que lhes assegurassem inteiro domínio do espaço, configurando-se uma situação de convivência sob a forma de enclaves e/ou mistura (ecótonos).

A turfa analisada insere-se na subunidade Fazenda Boa Vista Alta, na planície de inundação do rio Esperança (Figura 1). Nesse local ( $\left.22^{\circ} 36^{\prime} 34^{\prime \prime} \mathrm{S}, 53^{\circ} 11^{\prime} 49^{\prime \prime} \mathrm{W}\right)$ encontra-se uma série de pequenas colinas, entre 5 a $10 \mathrm{~m}$ de altura, orientada seguindo a direção norte-sul, com aproximadamente $10 \mathrm{~km}$, distanciadas em $2 \mathrm{~km}$ e identificadas como paleodunas formadas há pelo menos 3.700 anos AP (Parolin \& Stevaux, 2001; Figura 2).

\section{MÉTODOS}

O levantamento cartográfico foi realizado a partir do mapa geomorfológico apresentado por Stevaux (1993) e Parolin \& Stevaux (2001), bem como de fotografias aéreas na escala de 1:60.000 (sobrevôo 1966) e cartas topográficas de Loanda folha SF-22-Y-A-V e SF 22-Y-A nas escalas de 1:100.000 e 1:250.000. Os pontos de amostragem foram posicionados através de GPS.
Foram extraídos testemunhos (sondagens 1, 2 e 3) por meio de sonda vibratória vibrocore (Martin \& Fleyor, 1989) nas margens do rio Esperança (Figuras 1 e 2). Foram realizadas oito datações: quatro pelo método da termoluminescência (uma na sonda 3 na profundidade de $250 \mathrm{~cm}$ e três na paleoduna) e quatro por ${ }^{14} \mathrm{C}$ (nas profundidades de 30, 130, 220 e $240 \mathrm{~cm}$ ) (Figura 2). Com o objetivo determinar os valores de plantas $\mathrm{C}_{3}$ (vegetação arbórea) e $\mathrm{C}_{4}$ (vegetação herbácea, composta predominantemente de poáceas e ciperáceas), foram processadas sete amostras da sonda 2 (intervalos de aproximadamente $15 \mathrm{~cm}$, com profundidade máxima de 130 $\mathrm{cm}$ ) para determinação do teor de ${ }^{13} \mathrm{C}$ (Figura 3 ).

Construiu-se um palinodiagrama de composição taxonômica com freqüência percentual de palinomorfos e valores de ${ }^{13} \mathrm{C}$ dos perfis estudados (Figura 3). Para a análise palinológica foram elaboradas lâminas de trinta níveis estratigráficos distintos, no entanto, foram encontrados grãos de pólen e esporos em vinte níveis (Tabela 1).

As amostras foram tratadas com ácido clorídrico (10\%) e hidróxido de potássio (10\%). Aplicou-se o método de separação entre as substâncias inorgânicas e orgânicas através de líquido denso (solução aquosa de cloreto de zinco de densidade $2,2 \mathrm{~g} / \mathrm{cm}^{3}$ ), conforme técnica descrita por Faegri \& Iversen (1975). Após o tratamento químico, as amostras foram montadas em lâminas com gelatina-glicerinada. As lâminas foram depositadas no Laboratório de Palinologia do Grupo de Estudos do Meio Ambiente da Universidade Estadual de Maringá (Catálogo GEMA: 01/2004) (Tabela 1). 


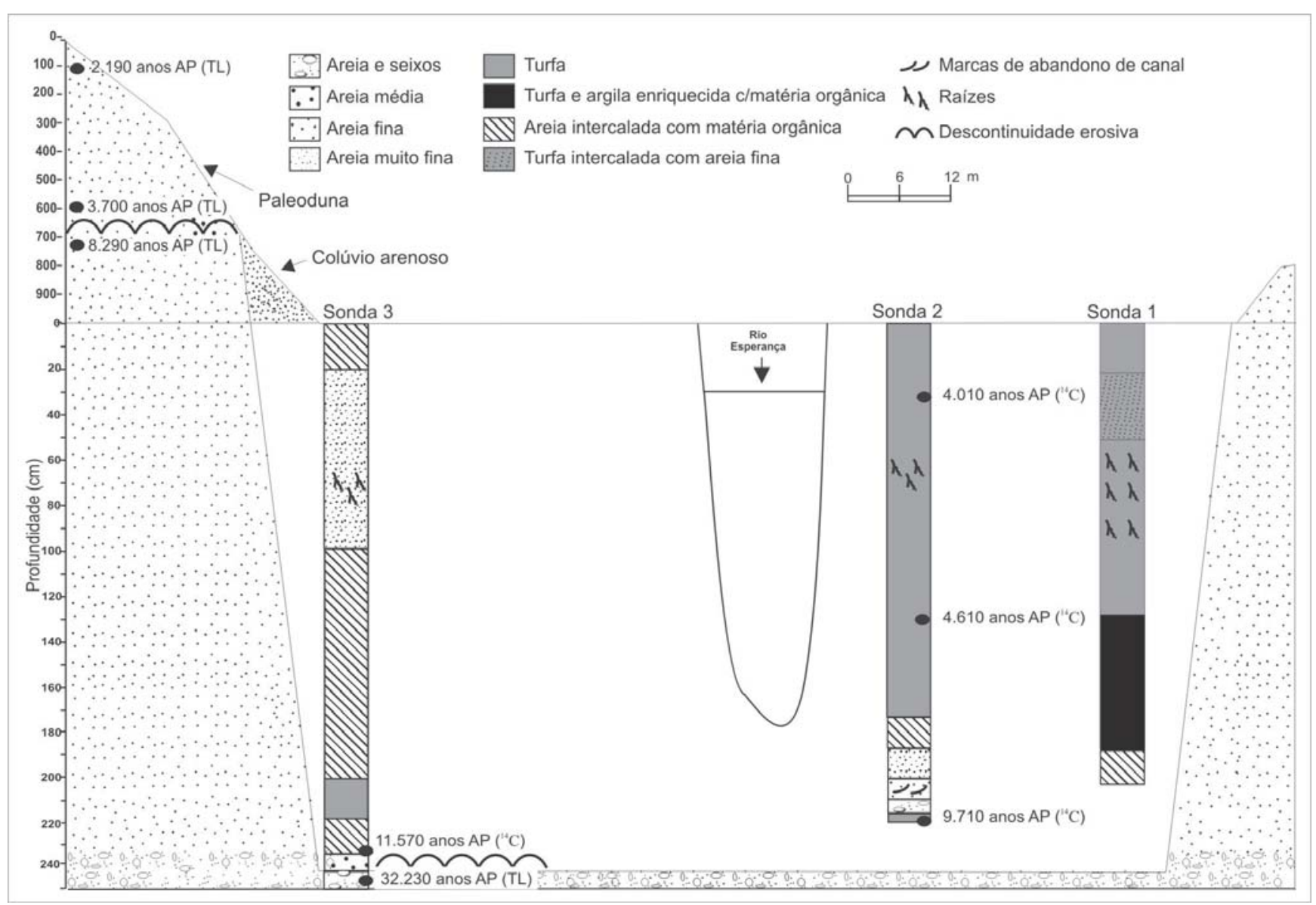

Figura 2. Perfis estudados: litologia, idades absolutas e posicionamento da paleoduna (adaptado de Parolin \& Stevaux, 2001). Figure 2. Studied core profiles: litology, absolute ages and position of paleodune (adapted from Parolin \& Stevaux, 2001).

Tabela 1. Sondas, profundidade $(\mathrm{em} \mathrm{cm})$ e quantidade de lâminas estudadas.

Table 1. Cores, depth (in $\mathrm{cm}$ ), and quantity of studied slides.

\begin{tabular}{c|lc}
\hline Sonda & Profundidade (cm) & $\mathbf{n}^{\circ}$ de lâminas \\
\hline 1 & $0,32,55-60,95-105,158-165$, & 13 \\
& 200 & 28 \\
2 & $0,10,20,30,40,50-60,60$, & \\
3 & $70,80,90,145-150,190,210$ & 3 \\
\hline
\end{tabular}

A identificação taxonômica dos grãos de pólen e dos esporos foi feita com base nos trabalhos de Barth et al. (1976), Neves \& Lorscheitter (1992; 1995), Garcia (1997; 1998), Lorscheitter et al. (1998; 1999), Coelho \& Barth (2000) e na coleção de referência de pólen e de esporos de plantas recentes pertencente ao Herbário do Núcleo de Pesquisa em Limnologia, Ictiologia e Aqüicultura da Universidade Estadual de Maringá.

Os estudos palinológicos além de pólen e esporos de plantas vasculares incluíram também a determinação de zigosporos e colônias de algas clorofíceas que frequentemente se encontravam nas amostras e às vezes em quantidades significativas. O uso e a importância dos zigosporos e colônias de algas clorofíceas para a reconstrução paleoambiental e paleoclimática estão presentes nos trabalhos de Van Geel (1978), Van Gell \& Van der Hammen (1978), Jankovská \&
Komárek (2000), Medeanic et al. (2003), entre outros. Os zigosporos e colônias de algas clorófitas foram determinados com base nos trabalhos de Van Geel (1976), Guy-Ohlson (1992), Canter-Lund (1995), Van der Hoek \& Mannand (1995), Komárek \& Jankovská (2001), entre outros.

Os palinodiagramas foram elaborados por meio do programa Tilia e Tiliagraf(Grimm, 1987). A interpretação dos dados palinológicos foi realizada valendo-se da razão entre palinomorfos de diferentes tipos, ou seja: pólen arbóreo, pólen herbáceo, pólen aquático, esporos de pteridófitas e briófitas, e zigosporos e colônias de clorófitas. A soma total expressa na Figura 3 significa a quantidade total de todos os grãos de palinomorfos encontrados e contados. A soma total expressa na Figura 4 significa a quantidade total de zigosporos e colônias de algas clorófitas encontradas nas amostras. Além dessas, os esporos de fungos encontrados nas amostras foram incluídos na contagem de palinomorfos. As identificações de esporos de fungos não foram realizadas, pois atualmente a sua taxonomia e aplicações nos estudos paleoambientais ainda são de difícil entendimento. Somaramse também as quantidades de fragmentos de partículas de carvões representados na Figura 5, onde foram inseridas fotomicrografias dos principais táxons de palinomorfos encontrados e a visão geral da distribuição de matéria orgânica nas lâminas. 


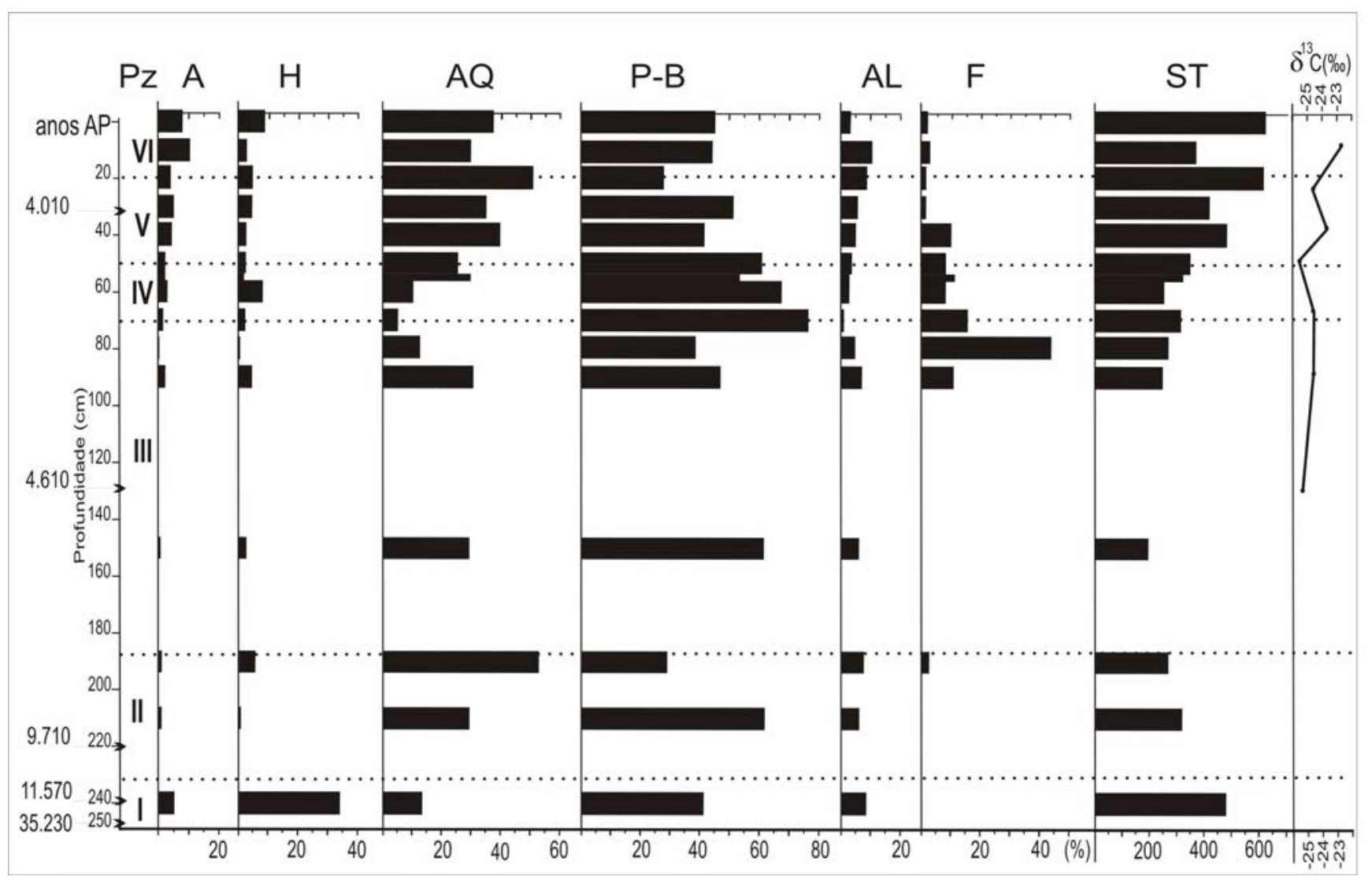

Figura 3. Palinodiagrama com a composição taxonômica, freqüência percentual de palinomorfos e valores de ${ }^{13} \mathrm{C}$ do perfil estudado. Abreviaturas: Pz, palinozonas; A, grãos de pólen arbóreos; H, grãos de pólen herbáceos; Aq, aquáticos; P-B, esporos de pteridófitas e briófitas; Al, algas; $\mathbf{F}$, fungos; $\mathbf{S T}$, soma total.

Figure 3. Palynodiagramme with taxa composition, percentile frequency of palynomorphs and values of ${ }^{13} \mathrm{C}$ of the studied profile. Abbreviations: Pz, palinozones; A, tree pollen grains; H, herb pollen grains; Aq, aquatic pollen grains; Al, algae; F, fungi; ST, total sum.

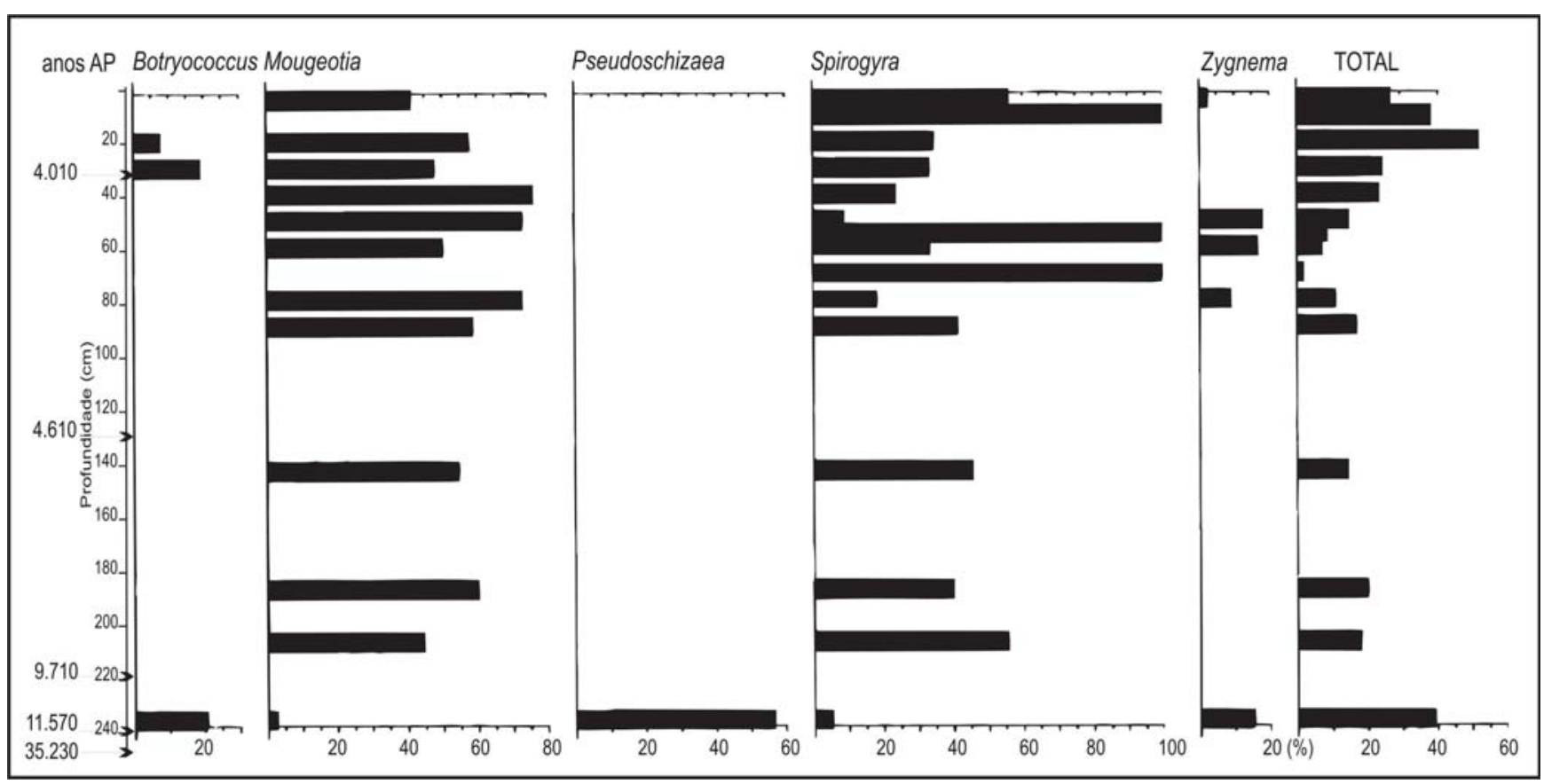

Figura 4. Diagrama de percentual de zigosporos e colônias de algas do perfil estudado.

Figure 4. Percentage diagramme of zygospores and colonies of algae from the studied profile. 


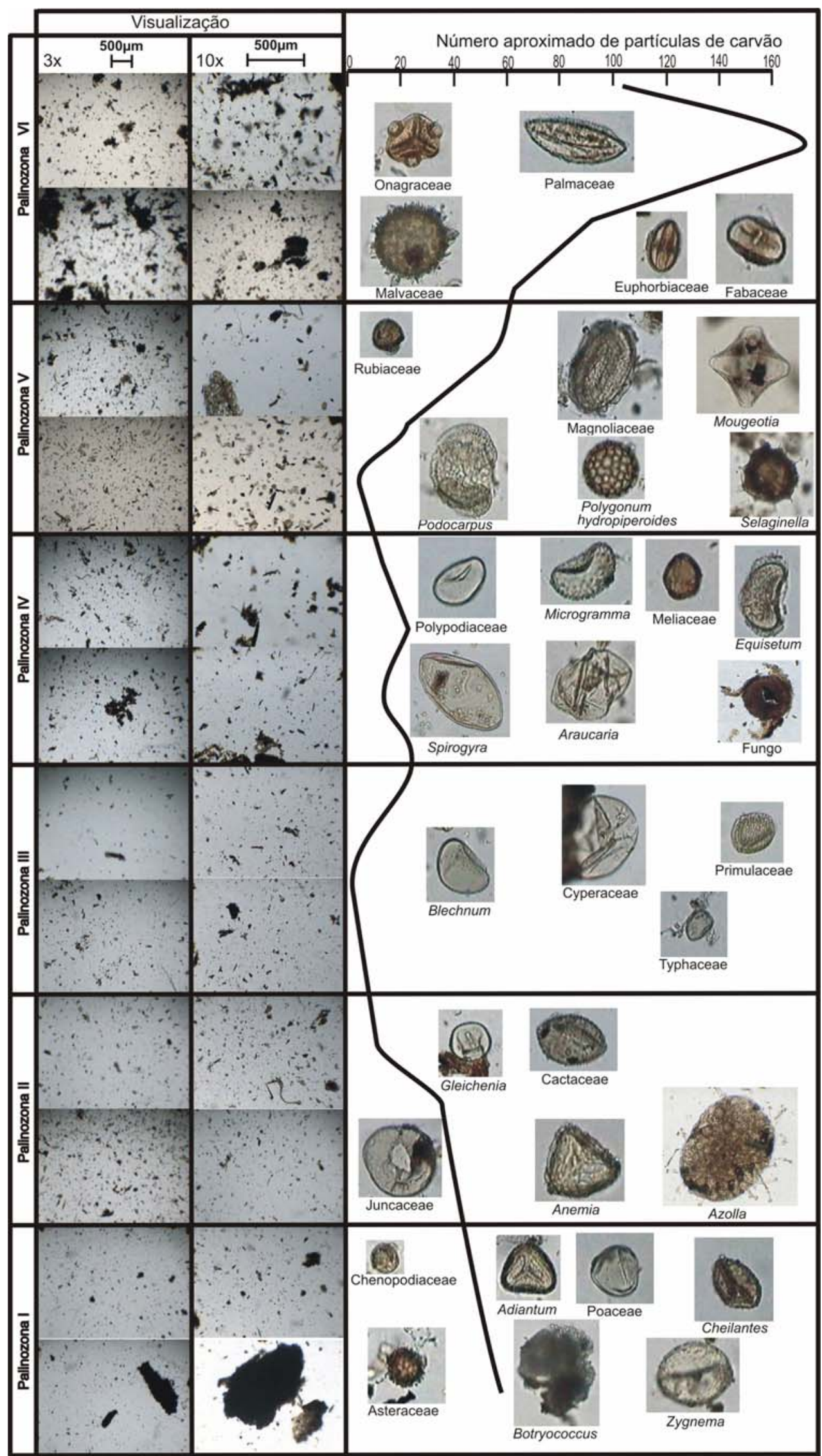

Figura 5. Fotomicrografias da distribuição de matéria orgânica nas lâminas (3x e 10x) com número aproximado de partículas de carvão. Figure 5. Photomicrographs of the distribution of organic matter in the slides (3x and 10x) with approximate number of particles of charcoal. 


\section{RESULTADOS E DISCUSSÃO}

Os valores de ${ }^{13} \mathrm{C}$ variaram entre $-25,5$ e $-22,7 \%$ (Figura 3 ), indicando provável predomínio de plantas $\mathrm{C} 3$ (árvores e/ou gramíneas $\mathrm{C}_{3}$ ) (Pessenda et al., 1998; Gouveia et al., 1999). Considerando-se que o material turfoso esteve sob coluna d'água, aumentam as possibilidades da presença de gramíneas $\mathrm{C}_{3}$, que apresentam a característica de localizar-se em ambientes depressivos úmidos (Mofatto, 2005) Segundo Calheiros (2003) a maior concentração do $\mathrm{C}_{3}$ ocorre em plantas vasculares

Com base na relação percentual entre os palinomorfos (pólen arbóreo, pólen herbáceo, esporos de briófitas e pteridófitas e zigosporos e colônias de algas), determinaramse seis palinozonas (Figura 3). A lista completa de táxons de pólen e esporos de plantas terrestres e aquáticas e sua ocorrência nas 20 amostras bem como soma total de grãos contados estão informados na Tabela 2.

\section{Palinozona I}

Corresponde ao intervalo entre 250 a $230 \mathrm{~cm}$ da sonda 3 , onde uma amostra de turfa da profundidade $240 \mathrm{~cm}$ foi datada por ${ }^{14} \mathrm{C}(11.570 \pm 80$ anos AP). Litologicamente, a turfa apresenta na base uma camada de seixos e areia, que foi datada por termoluminescência em 35.230 anos AP $(250 \mathrm{~cm})$ (Figura 2). Suspeita-se que a mesma possa ser base do terraço Fazenda Boa Vista, descrito por Stevaux et al. (1997). Esta zona apresenta raros exemplares de pólen arbóreo $(5 \%)$, pólen herbáceo (34\%), pólen de plantas aquáticas (13\%), esporos de briófitas e pteridófitas (40\%) e zigosporos e colônias de algas (8\%) (Figura 3). O pólen arbóreo é representado por Moraceae-Urticaceae, Palmae e Rubiaceae (Tabela 2). O pólen herbáceo é variável (Asteraceae, Chenopodiaceae e Poaceae são predominantes). Entre o pólen aquático e semiaquático, encontram-se com freqüência: Polygonum hydropiperoides, Cyperaceae e Typhaceae. Entre os esporos de briófitas predomina Phaeoceros. Os esporos de Pteridaceae são mais freqüentes nesta palinozona. Quanto às algas, registra-se a presença de Botryococcus, Mougeotia, Pseudoschizaea, Spirogyra e Zygnema (Figura 4).

Tendo por base a quantificação dos resultados, pode-se caracterizar essa etapa pelo predomínio de campos com significativa freqüência de plantas herbáceas-xerófitas (Chenopodiaceae e Amaranthaceae). Entre pólen de árvores e arbustos tem-se a freqüência significativa de xerófitas da família Rubiaceae. Ao que tudo indica, os banhados sempre estiveram presentes nesta região, sendo marcados pela ocorrência de esporos de briófitas de Anthoceros, Phaeoceros e Sphagnum, algas de Botryococcus, Spirogyra e Pseudoschizaea (Tabela 2 e Figura 4). Provavelmente, o clima tenha sido seco continental, com temperaturas mais baixas do que as temperaturas recentes. Esse período seco, com datações similares, foi descrito na região do Brasil Central por Ledru (1993) e Thomas \& Thorp (1995), na região dos campos gerais no Estado do Paraná por Behling (1997), que sugeriu a predominância de campos entre 12.480 e 9.660 anos AP com temperaturas entre $3^{\circ}$ e $5^{\circ} \mathrm{C}$ mais baixas que as atuais.
$\mathrm{Na}$ área de estudo na planície do rio Paraná, essa fase seca também é corroborada pelos trabalhos de Jabur (1992) e Stevaux (1993, 1994a, 2000).

\section{Palinozona II}

Corresponde a duas amostras do intervalo de 230 a 190 cm da sonda 2, datados por ${ }^{14} \mathrm{C}$ em $9.710 \pm 80$ anos AP (profundidade $220 \mathrm{~cm}$ ). É caracterizada da base para o topo por areia intercalada com matéria orgânica, turfa, areia fina e depósitos de canal fluvial (Figura 2). A ocorrência de pólen arbóreo e herbáceo não ultrapassa a 6\% (Figura 3). Entre o pólen arbóreo encontram-se, esporadicamente, Apocynaceae, Euphorbiaceae, Magnoliaceae e Rubiaceae. Os dois pólens de Cactaceae foram registrados no topo desta palinozona (Tabela 2). Pólens herbáceos são representados por Amaranthaceae, Asteraceae e Poaceae (Tabela 2). Constatase um aumento significativo de pólen aquático (Cyperaceae e Polygonum hydropiperoides) no topo desta palinozona (de 30 para 51\%). As quantidades de esporos de briófitas e pteridófitas (Blechnum, Gleichenia e Microgramma) figuram entre 62 e $30 \%$ diminuindo para o topo dessa palinozona (Figura 3). As algas apresentam uma freqüência de 6 a 8\%, apenas com dois táxons, Mougeotia e Spirogyra (Figura 4), cuja presença pode evidenciar a existência de um paleocanal. A ausência de colônias de Botryococcus e zigosporos de Pseudoscizaea pode confirmar essa sugestão. Os esporos de fungos ocorrem em pequena quantidade, não ultrapassando $3 \%$.

Verifica-se o acréscimo significativo de esporos de pteridófitas em relação à palinozona anterior, indicando uma pequena elevação da umidade, mas ainda sob o domínio de um clima seco continental com temperaturas mais baixas que as recentes, que se confirma pela freqüência notável de pólen de Amaranthaceae e Rubiaceae e rara freqüência de pólen arbóreo (Tabela 2). Foram encontradas numerosas partículas de carvão de tamanhos e contornos diferentes (diâmetro entre 5 e $200 \mu \mathrm{m}$ ), evidenciando a provável ocorrência de queimadas (Figura 5). É possível supor que a vegetação arbóreoarbustiva encontrava-se nesse período concentrada ao redor dos corpos de água. Essa fase mais seca na região estudada também foi constatada por Jabur (1992) e Stevaux (1993, 1994a, 2000). No nordeste da Argentina $\left(23^{\circ}\right.$ a $\left.30^{\circ} \mathrm{S}\right)$, tal situação foi descrita por Iriondo \& Garcia (1993).

\section{Palinozona III}

Determinada em quatro amostras no intervalo de 190 a 70 cm da sonda 2, datada por ${ }^{14} \mathrm{C}$ em $4.610 \pm 70$ anos AP na profundidade de $130 \mathrm{~cm}$. Os sedimentos da base para o topo constituem-se de areia intercalada com matéria orgânica e turfa (Figura 2). A ocorrência de pólen arbóreo é rara (1-3\%) (Figura 3), com predominânica de Palmae, MoraceaeUrticaceae, Piperaceae e Sapindaceae (Tabela 2). Os percentuais de pólen herbáceo não ultrapassam 5\% (predominância de Poaceae). Predominam nesta palinozona pólen de plantas aquáticas que diminuem em direção ao topo (de 29 para 5\%); no entanto, observa-se relativo aumento de esporos de pteridófitas (Dryopteris, Equisetum, 
Tabela 2. Composição taxonômica de grãos de pólen e esporos (sondas 1, 2 e 3) e sua freqüência em grãos nas palinozonas. Table 2. Identified pollen grains and spore taxa (cores 1,2 and 3) and their frequency in grains from the palynozones.

\begin{tabular}{|c|c|c|c|c|c|c|c|c|c|c|c|c|c|c|c|c|}
\hline \multirow{3}{*}{\multicolumn{2}{|c|}{ Pólen e Esporos }} & \multicolumn{15}{|c|}{ Palizonas e Profundidade $(\mathrm{cm})$} \\
\hline & & \multicolumn{2}{|c|}{ VI } & \multicolumn{3}{|c|}{$\mathbf{v}$} & \multicolumn{3}{|c|}{ IV } & \multicolumn{4}{|c|}{ III } & \multicolumn{2}{|c|}{ II } & \multirow{2}{*}{\begin{tabular}{|c|}
1 \\
230 \\
\end{tabular}} \\
\hline & & 0 & 10 & 20 & 30 & 40 & 50 & 55 & 60 & 70 & 80 & 90 & 150 & 190 & 220 & \\
\hline \multirow{18}{*}{ 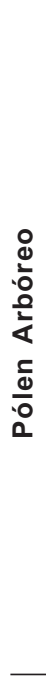 } & Arauaria (Bertol.) Kuntze 1898 & & & & & 1 & 2 & 1 & 2 & & & 1 & & & & \\
\hline & Podocarpus L' Hér. Ex Persoon 1807 & & & & & 2 & 2 & & & & & & & & & \\
\hline & Acanthaceae & 1 & & 4 & & & & & & & & & & & & \\
\hline & Apocynaceae & 5 & 4 & $\begin{array}{l}4 \\
2\end{array}$ & 6 & 11 & 1 & & & & & & & & 1 & \\
\hline & $\begin{array}{l}\text { Araliaceae } \\
\text { Bauhinia Lineu } 1753 \text { (?) }\end{array}$ & & & 2 & 3 & 2 & & & & & & & & & & \\
\hline & Cactaceae & 4 & & & & & & & & & & & & 2 & & \\
\hline & Calliandra Beth 1840 (?) & & & & & & & & 1 & & & & & & & \\
\hline & Euphorbiaceae & 2 & & 1 & & & & & & & & & & & 1 & \\
\hline & Fabaceae & 1 & 12 & 4 & 3 & 2 & & & 1 & & & 1 & & & & \\
\hline & $\begin{array}{l}\text { Fabaceae (Machaerium Persoon 1807) } \\
\text { Fabaceae (Parapiptadenia Brenan1963) }\end{array}$ & & 12 & 4 & & 1 & & & & & & & & & & \\
\hline & Magnoliaceae & & & 1 & & & & & & & & & & & & \\
\hline & Melastomaceae & & & & & & & 1 & & & & & & 1 & & \\
\hline & Miliaceae & & 2 & & 3 & 1 & & & & & & & & & & \\
\hline & $\begin{array}{l}\text { Moraceae-Urticaceae } \\
\text { Oxidaliaceae }\end{array}$ & 2 & 2 & 1 & & & & & & & & 3 & & & & 6 \\
\hline & Palmae & 30 & 5 & & 6 & 2 & & 4 & & & 1 & & & & & 12 \\
\hline & Piperaceae & 5 & 2 & 1 & & & & & 1 & & & & 2 & & & \\
\hline & Rubiaceae & & & & & & & & & & & & & 2 & 2 & 6 \\
\hline & $\begin{array}{l}\text { Sapindaceae } \\
\text { Smilax Lineu } 1735\end{array}$ & & & $\begin{array}{l}4 \\
1\end{array}$ & 3 & & & & 1 & 2 & & & & & & \\
\hline \multirow{9}{*}{ 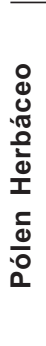 } & Amaranthaceae & & & & & & & & & & & & & 3 & & 9 \\
\hline & Apaceae & & & & & & & & & & & & & & & 2 \\
\hline & Asteraceae & 13 & 3 & 2 & 2 & & 1 & & 1 & & & 4 & 2 & 3 & & 60 \\
\hline & $\begin{array}{l}\text { Chenopodiaceae } \\
\text { Cichoreaceae (Vernonia Schreb1791) }\end{array}$ & & & & & & & & & & & & & & & $\begin{array}{l}8 \\
4\end{array}$ \\
\hline & Commelianaceae & 2 & & & & & & & & & & & & & & 4 \\
\hline & Convolvulaceae & & & & & & & & & & & & & & & 1 \\
\hline & Malvaceae & 9 & 5 & 4 & 5 & 3 & & & 1 & & & & & & & \\
\hline & Primulaceae & 1 & & & & & & & & & & & 2 & & & \\
\hline & $\begin{array}{l}\text { Poaceae } \\
\text { Polygonaceae (Rumex Lineu 1735) }\end{array}$ & $\begin{array}{c}24 \\
1\end{array}$ & 3 & 20 & 10 & 5 & 4 & 4 & 20 & 5 & 2 & 5 & 2 & 12 & 2 & 79 \\
\hline \multirow{7}{*}{$\begin{array}{l}0 \\
0 \\
\frac{0}{0} \\
\frac{0}{0} \\
0 \\
\frac{0}{0} \\
\frac{c}{0} \\
\frac{0}{0} \\
0\end{array}$} & Azolla Lamark 1783 & & & & & 2 & & & 1 & & & & & 3 & & 2 \\
\hline & $\begin{array}{l}\text { Cyperaceae } \\
\text { Dispsacaceae }\end{array}$ & 24 & $\begin{array}{c}28 \\
2\end{array}$ & 32 & 30 & 32 & 50 & 61 & 13 & 6 & 21 & 42 & 41 & 116 & 57 & 47 \\
\hline & Juncaceae & & & & & & & & & & & & & & 1 & \\
\hline & Lemnaceae & & 9 & & & & & & & & & & & & & \\
\hline & Onagraceae (Ludwigia Lineu 1753) & 9 & 13 & 25 & 10 & & 4 & & & & & & 2 & & & \\
\hline & $\begin{array}{l}\text { Polygnum hydropperoldes Lineu 1/53 } \\
\text { Typhaceae }\end{array}$ & & & 266 & 100 & 155 & $\begin{array}{c}30 \\
4\end{array}$ & 31 & 15 & 11 & $\begin{array}{c}3 \\
10\end{array}$ & 32 & 15 & $\begin{array}{l}18 \\
5\end{array}$ & 39 & $\begin{array}{l}5 \\
8\end{array}$ \\
\hline & Ulotriculaceae & & & & & & & 2 & & & & & & & & \\
\hline \multirow{12}{*}{ 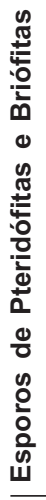 } & Anemia Swartz 1806 & 16 & & & 1 & & & & 1 & & & & & & & \\
\hline & $\begin{array}{l}\text { Anthoceros Lineu } 1753 \\
\text { Adiantum Lineu } 1753\end{array}$ & & & & & & & & & & & & & & & 1 \\
\hline & Botrychium Swartz 1800 (?) & & & 2 & & & & & & & 1 & & & & & \\
\hline & Blechnum Lineu 1753 & & & & & & & & & & & & & & 43 & \\
\hline & Cheilanthes Swartz 1806 & & & & & & & & & & & & & & & 2 \\
\hline & Dryopteris Adanson 1763 (?) & 5 & 3 & 5 & & & & & & 30 & & & & & & \\
\hline & Equisetum Lineu 1753 & & & 3 & & & 10 & 2 & 28 & 10 & 30 & 2 & & & 0 & \\
\hline & Lycopodium Lineu 1753 & & 7 & & & & & & & & & & & & & 2 \\
\hline & $\begin{array}{l}\text { Microgramma (Scharader) Presl } 1836 \\
\text { Phaeoceros Prosk } 1951\end{array}$ & 49 & & & & 1 & 2 & & 10 & 28 & 3 & 10 & & 1 & 5 & $\begin{array}{l}2 \\
97\end{array}$ \\
\hline & Pteridaceae & 10 & 3 & & & & & & 1 & & & 1 & 6 & 1 & & 73 \\
\hline & $\begin{array}{l}\text { Polypodiaceae } \\
\text { Selaginella Palisot-Beavois } 1804\end{array}$ & 170 & 154 & $\begin{array}{c}159 \\
1\end{array}$ & 213 & 195 & 198 & 168 & 128 & 174 & 70 & 138 & 115 & $\begin{array}{c}71 \\
4\end{array}$ & 145 & 8 \\
\hline & Sphagnum Lineu 1753 & & & & & & & & & & & & & & & 6 \\
\hline \multirow{4}{*}{$\begin{array}{l}\frac{0}{\pi} \\
\text { ơ } \\
\frac{\pi}{4}\end{array}$} & Botryococcus Kützing 1849 & & & 4 & 5 & & & & & & & & & & & 8 \\
\hline & $\begin{array}{l}\text { Mougeotia C. A. Agardth } 1824 \\
\text { Pseydiscquzaea Theig \& Fr.Ex. R.Potoni } 1988\end{array}$ & 10 & & 27 & 12 & 18 & 7 & & 4 & & 7 & 8 & 9 & 9 & $\begin{array}{c}8 \\
22\end{array}$ & 1 \\
\hline & Spirogyra Link 1820 & 14 & 37 & 18 & 8 & 6 & 1 & 8 & 3 & 3 & 2 & 6 & 4 & 12 & 11 & 2 \\
\hline & Zygnema C. A. Agardth 1824 & 1 & & & & & 2 & & 1 & & 1 & & & & & 6 \\
\hline & ngos & 12 & 11 & 12 & 8 & 48 & 31 & 39 & 22 & 47 & 120 & & & 8 & & \\
\hline To & & 624 & 377 & 607 & 428 & 487 & 349 & 321 & 255 & 316 & 271 & 253 & 200 & 271 & 318 & 480 \\
\hline
\end{tabular}


Microgramma e Polypodiaceae) com percentuais entre 40 e $76 \%$ para o topo desta zona. Nesta palinozona ocorre uma pequena quantidade de zigosporos e colônias de algas (entre 1 e $8 \%$ ) em relação à soma total de palinomorfos, com destaque para Mougeotia, Spirogyra e Zygnema (apenas no topo da palinozona) (Figura 4). Os esporos de fungos somaram próximo ao topo desta zona $44 \%$. Nesta palinozona são raras as partículas de carvões (Figura 5). A rara freqüência de palinomorfos nesta palinozona, especialmente na sua base, pode evidenciar condições não favoráveis para a preservação dos palinomorfos. Tal fato pode estar associado à intensa atividade eólica, descrita na região para essa época (Parolin \& Stevaux, 2001), que provocou intensa remobilização de sedimentos com provável destruição de palinomorfos e matéria orgânica.

A paleoduna situada ao lado da turfeira estudada (Figura 2) possui idades próximas há 4.000 anos AP, sugerindo para essa época um clima mais seco que a etapa correspondente à palinozona II. A redução das precipitações pluviométricas, provavelmente, provocou o rebaixamento do nível de água da turfeira. A presença de areia intercalada com matéria orgânica nesta palinozona, poderia ter sido formada como resultado da intensificação de processos eólicos (Figura 2). Os resultados sugerem a existência de uma fase mais seca na região há 4.610 anos AP durante a vigência do primeiro evento úmido na região descrito por Stevaux (1993, 1994a, 1994b), também citado para o Brasil Central em Salgado-Laboriau (1997). Para essa mesma região (latitude de $19^{\circ} \mathrm{S}$ ), Ledru (1993) relatou um tempo árido há 5.000 anos AP.

\section{Palinozona IV}

Corresponde ao intervalo de turfa 70 a $50 \mathrm{~cm}$ das sondas 1 e 2 (Figura 2). Os resultados mostram um pequeno aumento na freqüência de grãos de pólen arbóreo (Figura 3), entretanto com percentuais menores que 3\% (Apocynaceae, Calliandra, Fabaceae, Melastomaceae, Palmae, Piperaceae e Sapindaceae) (Tabela 2). Foram registrados pólen de Araucaria e Podocarpus os quais, provavelmente, foram transportados pelo vento ou correntes aquáticas de regiões da sua distribuição. Verifica-se um aumento de pólen herbáceo (encontra-se pólen de plantas mesófitas - Asteraceae, Convolvulaceae e Poaceae), chegando a 9\%. Pólens de plantas aquáticas (Cyperaceae e Polygonum hydropiperoides) atingem percentuais entre 12 e $30 \%$ com aumento de quantidade em direção ao topo da palinozona (Figura 3). Encontra-se uma expressiva quantidade de esporos de pteridófitas - Equisetum, Microgramma e Polypodiaceae (entre 54 e 68\%). Os zigosporos de algas são raros (3-4\%), sendo representadas por Mougeotia, Spirogyra, e Zygnema (Figura 4). Os esporos de fungos sofreram uma redução nos percentuais (40-9\%) em relação à palinozona III (Figura 3).

Os dados sugerem uma pequena melhora nas condições climáticas em relação à palinozona anterior, expressada pelo aumento notável de pteridófitas e ausência de pólen de plantas xerófitas; no entanto, ainda sob o domínio de um clima relativamente seco. Essa pequena melhoria climática pode estar correlacionada ao primeiro evento úmido descrito por Stevaux (1993, 1994a, 1994b) para a região do alto rio Paraná.

\section{Palinozona V}

Corresponde às três amostras de turfa, no intervalo 50 a 20 $\mathrm{cm}$ da sonda 2 (Figura 2). A amostra do intervalo $29-35 \mathrm{~cm}$ foi datada por ${ }^{14} \mathrm{C}$ em $4.010 \pm 80$ anos AP. Registra-se nesta palinozona um pequeno aumento na freqüência de grãos de pólen arbóreo (4-5\%) (Figura 3) e um aumento notável da sua diversidade taxonômica (Acanthaceae, Apocynaceae, Araliaceae, Bauhinia, Fabaceae, Magnoliaceae, Meliaceae, Palmae, Piperaceae e Sapindaceae) (Tabela 2). Na base da palinozona foram registrados pólens de Araucaria e Podocarpus. Pólen herbáceo com discreto aumento em relação ao topo da palinozona anterior (3-5\%), sendo representado por Asteraceae, Malvaceae e Poaceae (Tabela 2). É notável a presença significativa de pólens de plantas aquáticas Polygonum hydropiperoides, Ludwigia e Cyperaceae com percentuais chegando a $53 \%$ para o topo desta palinozona. Registra-se uma redução nos percentuais de esporos de pteridófitas (com predominância de Polypodiaceae) em relação à palinozona anterior (entre 30 e 51\%). Encontram-se também esporos de um pteridófito aquático (Azolla). As algas apresentam aumento nos percentuais em direção ao topo da palinozona (5-9\%). Os táxons de algas encontrados foram Mougeotia, Spirogyra e Botryococcus (Figura 4). A quantidade de esporos de fungos sofre redução em direção ao topo da palinozona de 10 para $2 \%$. Os dados sugerem um aumento da influência dos influxos de águas (maior volume de água do rio Esperança, por melhoria climática ou pelo represamento deste quando das cheias do rio Paraná), que podiam interferir no desenvolvimento da turfa, ampliar a sua área e favorecer o desenvolvimento de plantas aquáticas. É notável nesta palinozona o aumento gradativo da quantidade das partículas de carvões (Figura 5).

\section{Palinozona VI}

Corresponde ao intervalo de turfa de $20 \mathrm{a} 0 \mathrm{~cm}$ das sondas 1 e 2 (Figura 2). Caracteriza-se pelo aumento na diversidade taxonômica de pólen arbóreo (até 10\%) (Figura 3), sendo representados por Acanthaceae, Apocynaceae, Calliandra, Fabaceae, Meliaceae, Moraceae-Urticaceae, Palmae e Piperaceae (Tabela 2). O pólen herbáceo aumentou de 4 para 8\% (Figura 3), sendo mais freqüente o de plantas mesófitas (Asteraceae, Commelinaceae, Poaceae e Polygonaceae) (Tabela 2). Os percentuais de pólen de plantas aquáticas atingem $39 \%$ no topo do perfil (predominância de Polygonum hydropiperoides e presença de Cyperaceae, Lemnaceae e Dipsacaceae). Os esporos de pteridófitas (Anemia, Dryopteris, Microgramma, Pteridaceae e Polypodiaceae) chegam à faixa de $45 \%$. As algas apresentam percentuais entre 4 e $11 \%$ (topo), com destaque para os táxons Mougeotia, Spirogyra, e Zygnema (Figura 4). Os esporos de fungos não ultrapassam $4 \%$. A grande quantidade de partículas de carvão de diferentes contornos e tamanhos (diâmetro entre 5-100 $\mu \mathrm{m}$ ) sugerem a ocorrência de incêndios, provavelmente, de origem antrópica. A informação de Kashimoto \& Martins (2004) sobre registros 
de indígenas ceramistas na região há pelo menos 1.500 anos AP corrobora com a origem antrópica dos incêndios nesta região. $\mathrm{O}$ aumento de freqüência e diversidade taxonômica de pólen arbóreo e arbustivo aliado à grande quantidade de pólen aquático é sugestivo de um aumento nas precipitações pluviométricas (Figura 3 e Tabela 2). A quantidade total expressiva de palinomorfos encontrados nesta palinozona pode evidenciar um enriquecimento de cobertura vegetal sob condições de um aumento na umidade, bem como as condições favoráveis para preservação de palinomorfos. Argumenta-se, no entanto, que a redução de pólen arbóreo no topo desta palinozona deva-se, provavelmente, à ação antrópica representada pela intensa utilização das terras dessa região para a formação de pastagens desde a década de 1970 (Duarte, 1989; Mesquita, 1989), enquanto que a diminuição significativa das algas está relacionada, provavelmente, à própria alteração sazonal no nível de água da planície do rio Esperança.

Numa visão generalizada das lâminas (Figura 5), verificase que a maior abundância de matéria orgânica encontra-se nas palinozonas superiores (IV, V e VI) indicando aumento gradativo da umidade, enquanto nas palinozonas inferiores (I, II e III), a matéria orgânica apresenta-se amorfa e nas palinozonas (II e III) quase escassa. Provavelmente, este fato esteja ligado à maior aridez e atividade eólica (Parolin \& Stevaux, 2001), que causou empobrecimento notável da vegetação e sua produtividade biológica, bem como condições não favoráveis para a preservação da matéria orgânica nos sedimentos e, entre outras coisas, possibilidades de redeposição (Figura 3).

\section{CONCLUSÕES}

Com base nos resultados palinológicos e datações de idade absoluta dos sedimentos pela termoluminescência e ${ }^{14} \mathrm{C}$, foram feitas as reconstruções paleoambientais e paleoclimáticas que ocorreram durante o Holoceno na região de Taquarussu (MS). Os dados obtidos indicam oscilações climáticas notáveis durante o Holoceno, seco e relativamente continental durante o Holoceno Inferior e Médio e mais úmido desde Holoceno Tardio até o presente.

Valendo-se da análise da distribuição de diferentes palinomorfos, incluindo o pólen, esporos de plantas terrestres e aquáticas, zigosporos e colônias de algas clorofíceas, foram estabelecidas as diferentes etapas no desenvolvimento paleoambiental na região de Taquarussu. O estabelecimento de razões percentuais entre pólen arbóreo, herbáceo e aquático foi usado nas reconstruções paleoambientais terrestres cujas mudanças foram diretamente conectadas com oscilações do clima. As análises dos registros de zigosporos e colônias de algas clorofíceas foram importantes nas reconstruções paleoambientais. A sua presença constante em todas as amostras estudadas é uma evidencia sobre a formação da turfa numa bacia aquática, influenciada pelas correntes temporárias durante os períodos de aumento das precipitações pluviométricas.

A vegetação herbácea (asteráceas, ciperáceas e poáceas) predominou durante todo o Holoceno. A vegetação arbórea e arbustiva foi composta predominantemente por fabáceas, palmáceas e apocináceas com distribuição restrita. As épocas de maior distribuição de áreas florestais e aumento de sua diversidade provavelmente estão relacionadas principalmente com o aumento das precipitações pluviométricas.

Tais sugestões parecerem corroborar com um período de intensa aridez no Holoceno Inferior na planície de inundação do rio Paraná conforme discutido por Jabur (1992) e Stevaux (1993, 1994a, 1994b). Argumenta-se que o primeiro evento úmido que ocorreu durante Holoceno sugerido por estes autores entre 3.500 e 7.500 anos AP não tenha ocorrido com a mesma intensidade na região estudada ou então esse período esteja marcado por uma fase mais seca há 4.610 anos AP, pois os dados mostraram melhorias discretas das condições climáticas. As condições ambientais reconstruídas da palinozona III parecem estar correlacionadas à formação das paleodunas relatadas por Parolin \& Stevaux (2001).

Os dados relativos ao período atual estão em consonância com os trabalhos desenvolvidos por Barczysczyn (2001) e Medeanic \& Stevaux (2003) na região de Taquarussu, bem marcado de um lado pelo aumento relativo na quantidade de pólen arbóreo, provavelmente, cultivadas para o uso doméstico e pólen em quantidade anômala de plantas ruderais, e de outro lado pela presença freqüente e constante de partículas de carvões derivadas de queimadas.

\section{AGRADECIMENTOS}

Os autores agradecem ao CNPq e à CAPES (processo 884-16/04) pelas facilidades oferecidas no desenvolvimento deste trabalho; Olivo Nonato, proprietário da Fazenda Ouro Verde; Valdir Alves e José Antônio da Rocha pela ajuda prestada no trabalho de campo; Luiz C. R. Pessenda pelas analises de ${ }^{13} \mathrm{C}$; Maria Conceição de Souza e Kazue K. Kita pela atenção dispensada ao trabalho; e Maria de Moraes pela grande ajuda no laboratório.

\section{REFERÊNCIAS}

Barbosa, A.S.; Ribeiro, M.B. \& Shimitz, P.I. 1990. Cultura e ambiente em áreas de cerrado do sudoeste de Goiás. In: M.N. Pinto (ed.) Cerrado - caracterização ocupação e perspectivas. Brasília, Editora da UNB, p. 67-100.

Barczysczyn, O. 2001. Paleossolos na planície de inundação dor rio Paraná: caracterização e interpretação paleoambiental. Programa de Pós-Graduação em Geociências e Meio Ambiente, Universidade Estadual Paulista-Rio Claro. Dissertação de Mestrado, 83 p.

Barczysczyn, O.; Stevaux, J.C.; Medeanic, S., \& Nóbrega, M.T. 2001. Paleossolo da planície de inundação do rio Paraná e suas implicações paleohidrológicas e climáticas. In: CONGRESSO DA ASSOCIAÇÃO BRASILEIRA DE ESTUDOS DO QUATERNÁRIO, 8, 2001. Boletim, Imbé, p. 356-357.

Barth, O.M.; Barbosa, H.S. \& Macieira, E.G. 1976. Morfologia de pólen anemófilo e alergizante no Brasil VI - Graminae, Palmae, Typhaceae, Cupressaceae e Combretaceae. Memórias do Instituto Oswaldo Cruz, 74(3/4):347-359.

Behling, H. 1997. Late Quaternary vegetation, climate and fire history of the Araucaria forest and campos region from Serra 
Campos Gerais, Paraná State (South Brazil). Review of Palaeobotany and Palynology, 97:109-121

Calheiros, D.F. 2003. Influência do pulso de inundação na composição isotópica $\left({ }^{13} \mathrm{Ce}{ }^{,{ }^{, 15}} \mathrm{~N}\right)$ das fontes primárias de energia na planícies de inundação do rio Paraguai (Pantanal - MS). Programa de Pós-Graduação do Centro de Energia Nuclear na Agricultura, Universidade de São Paulo, Tese de Doutorado, 186 p.

Campos, J.B. \& Souza, M.C. 1997. Vegetação. In: A.E.A. Vazzoler; A.A. Agostinho \& N.S.Hahn (eds.) A Planície de Inundação do Alto Rio Paraná - Aspectos físicos, biológicos e socioeconômicos. Editora da Universidade de Maringá, p. 331-342.

Canter-Lund, H. 1995. Fresh water Algae. Their microscopic world explored. Biopress, $360 \mathrm{p}$.

Coelho, L.G. \& Barth, O.M. 2000. Morfologia polínica e habitat das espécies do gênero Alchornea (Euphorbiaceae) presentes nas matas de Santa Catarina, Sul do Brasil. Revista Universidade Guarulhos, Geociências (número especial), 5:228-230.

Coltrinari, L. 1993. Global Quaternary changes South American. Global Planetary Change, 7:11-23.

Duarte, A.C. 1989. Estrutura do espaço regional. In: IBGE (ed.) Geografia do Brasil Região centro-oeste, v.1, p. 263-267.

Faegri, K. \& Iversen, J. 1975. Text-book of pollen Analysis. Munksgaard, Copenhagen. Blackwell Scientific Publications, $295 \mathrm{p}$.

Garcia, M.J. 1997. Palinologia de turfeiras quaternárias do Médio Vale do Rio Paraíba do Sul, estado de São Paulo, Brasil. Parte I: Fungos, Algas, Briófitas e Pteridófitas. Revista Universidade de Guarulhos, Geociências, 2:148-165.

Garcia, M.J. 1998. Palinologia de turfeiras quaternárias do Médio Vale do Rio Paraíba do Sul, Estado de São Paulo, Brasil. Parte II: Gymnospermae e Magnoliophyta. Revista Universidade de Guarulhos, Geociências, 3(6):84-107.

Gouveia, S.E.M.; Pessenda, L.C.R.; Boulet, R.; Aravena, R. \& Schell-Ybert, R. 1999. Isótopos do carbono dos carvões e da matéria orgânica do solo em estudos de mudança de vegetação e clima no Quaternário e da taxa de formação de solos do Estado de São Paulo. Anais da Academia Brasileira de Ciências, 71(4II):969-980.

Grimm, E.C.C. 1987. CONISS: a fortran 77 Program for stratigraphically constrained cluster analysis the method of the incremental sum of squares. Pergamon Journal, 13:13-35.

Guy-Ohlson, D. 1992. Botryococcus as an aid in the interpretation of palaeoenvironment and depositional processes. Review of Palaeobotany and Palynology, 71:1-15.

Iriondo, M.H. \& Garcia, N.O. 1993. Climatic variations in the Argentina plains during the last 18.000 years. Palaeogeography, Palaeoclimatology, Palaeoecology, 101:209-220.

Iriondo, M.H. \& Kröhling, D.M. 1995. El sistema eólico Pampeano. In: Comunicación del Museo de Ciencias Naturales "Florentino Ameghino", 5(1):1-68.

Iriondo, M.H.; Krohling, D.M. \& Orfeo, O. 1997. La Formación Obera, un sedimento eólico tropical. In: CONGRESSO LATINOAMERICANO DE SEDIMENTOLOGIA, 1, 1997. Memórias, Sociedad Venezolana de Geologia,1:342-348.

Jabur, I.C. 1992. Análise paleoambiental do Quaternário superior na bacia do alto rio Paraná. Programa de Pós-Graduação em Geologia Regional, Universidade Estadual Paulista/Rio Claro. Tese de Doutorado, 184 p.

Jankovská, V. \& Komárek, J. 2000. Indicative value of Pediastrum and other coccal green algae in Palaeoecology. Folia Geobotanica, 5:59-82.

Kashimoto, E.M. \& Martins, G.R. 2004. Archaeology of the Holocene in the upper Paraná River, Mato Grosso do Sul State,
Brazil. Quaternary International, 114:67-86.

Komárek, J.\& Jankovská, V. 2001. Review of the green algal Genus Pediastrum: implication for pollen-analytical research. Berlin, Biblioteca Phycologica, $127 \mathrm{p}$.

Kramer, V.M.S. \& Stevaux, J.C. 1999. Thermoluminesce and magnetical susceptibility applied to paleoclimatic reconstruction of the Taquaruçu region (Center-Eastern Brazil), during the Holocene. Boletim Goiano de Geografia, 19:38-42.

Ledru, M.P. 1993. Late Quaternary evironmental and climatic changes in Central Brazil. Quaternary Research, 39:90-98.

Ledru, M.P.; Braga, P.I.S; Soubiès, F.; Martin, L.; Suguio, K. \& Turcq, B. 1996. The last 50,000 years in neotropics (Southern Brazil): evolution of vegetation and climate. Paleogeography, Paleoclimatology, Paleoecology, 123:239-259.

Lorscheitter, M.L.; Ashraf, A.R.; Bueno, R.M. \& Mosbrugger, V. 1998. Pteriodophyte spores of Rio Grande do Sul flora, Brazil, part I. Palaeontographica, Abt. B 246:1-113.

Lorscheitter, M.L.; Ashraf, A.R.; Bueno, R.M. \& Mosbrugger, V. 1999. Pteriodophyte spores of Rio Grande do Sul flora, Brazil, part II. Palaeontographica, Abt. B, 251:1-235.

Martin, L. \& Fleyor, J.M. 1989. Vibrotestemunhador leve: construção utilização e possibilidades. ABEQUA, 15 p. (Publicação Especial n.1)

Medeanic, S. \& Stevaux, J.C. 2003. Dados palinológicos e partículas de carvão: avaliação de impacto antrópico na região do alto rio Paraná durante o Holoceno In: CONGRESSO ABEQUA, IX, 2003. Anais de Resumos Expandidos, Recife, p. 26-29.

Medeanic, S.; Jankovská, V. \& Dillenburg, S.R., 2003. The implication of green algae (Chlorophyta) for palaeoecological reconstruction of the Holocene lagoon system in the Tramandaí Lagoon region, Rio Grande do Sul, Brazil. Acta Palaeobotânica, 43(1):113-123.

Mesquita, O.V. 1989. Agricultura. In: IBGE (ed.) Geografia do Brasil Região Centro-Oeste, v.1, p. 149-170.

Mofatto, M. 2005. Estudos multi/interdisciplinar de reconstrução da vegetação e clima na região do parque Estadual da Serra do Mar-Núcleo de Curucutu., São Paulo, C.P., no Quaternário tardio. Programa de Pós-Graduação em Ciências, Universidade de São Paulo, Piracicaba, Dissertação de Mestrado, 150 p.

Neves, P.C.P. \& Lorscheitter, M.L. 1992. Palinologia de sedimentos de uma mata tropical paludosa em Terra de Areia, planície costeira Norte, Rio Grande do Sul, Brasil. Descrições taxonômicas. Parte II: Gimnospermas e Angiospermas. Acta Geologica Leopoldensia, 36:83-114.

Neves, P.C.P. \& Lorscheitter, M.L. 1995. Palinologia de sedimentos de uma mata tropical paludosa em Terra de Areia, planície costeira Norte, Rio Grande do Sul, Brasil. Descrições taxonômicas. Parte I: Fungos, Algas, Briófitas, Pteridófitos, palinomorfos e outros fragmentos de invertebrados. Acta Geologica Leopoldensia, 41:45-82.

Nimer, E. 1989. Clima. In: IBGE (ed.) Geografia do Brasil Região Centro-Oeste, v.1, p. 23-34.

Parolin, M. \& Stevaux, J.C. 2001. Clima seco e formação de dunas eólicas durante o Holoceno Médio em Taquaruçu, Mato Grosso do Sul. Pesquisas em Geociências, 28(2):233-243.

Pessenda, L.C.R.; Gouveia, S.E.M.; Aravena, R.; Gomes, B.M.; Boulet, R. \& Ribeiro, A.S. $1998 .{ }^{14} \mathrm{C}$ dating and stable carbon isotopes of soil organic matter in forest-savana boudary áreas in the southern brasilian amazon region. Radiocarbon, 40(2): 1013-1022.

Salgado-Laboriau, M.L. 1997. Late Quaternary paleoclimate in the savannas of South America. Journal of Quaternary Science, 12(5):371-379. 
Santos, M.L. dos \& Stevaux, J.C. 2000. Facies and architectural analysis of channel macroforms sandy in the upper Paraná river. Quaternary International, 72:87-94

Souza, M.C. de; Kazue, K.K.; Romagnolo, M.B.; Tomazini, V.; Albuquerque, E.C.; Secorun, A.C. \& Miola, K.T.B. 2004. Riparian vegetation of the upper Paraná River floodplain, Paraná and Mato Grosso do Sul States, Brazil. In: A.A. Agostinho; L. Rodrigues; L.C. Gomes; S.M. Thomaz \& L.E. Miranda (eds.) Structure and functioning of the Paraná River and its floodplain, Editora da Universidade Estadual de Maringá, p. 233-238

Stevaux, J.C. 1993. O rio Paraná: geomorfogênese, sedimentologia e evolução quaternária de seu curso superior. Programa de Pós-Graduação em Geologia Sedimentar, Universidade de São Paulo, Tese de Doutorado, 142 p.

Stevaux, J.C. 1994a. Upper Paraná River (Brazil) geomorphology and paleoclimatology. Quaternary International, 21:143-161.

Stevaux, J.C. 1994b. Geomorfologia, sedimentologia e paleoclimatologia do Alto Curso do rio Paraná (Porto RicoPR). Boletim Paranaense de Geociências, 42:97-112.

Stevaux, J.C. 2000. Climatic events during the Late Pleistocene and Holocene in the Upper Paraná River: Correlation with NE Argentina and South-Central Brazil. Quaternary International, 72:73-85.

Stevaux, J.C. \& Santos M.L. dos. 1998. Paleohydrological changes in the upper Paraná River (Brazil) during the Late Quaternary: a faciological approach. Paleohydrology and Hydrological Science, 1:273-285.

Stevaux, J.C.; Souza Filho, E.E. \& Jabur, I.C. 1997. A história quaternária do rio Paraná em seu alto curso. In: A.E.A. de
Vazzoler; A.A. Agostinho \& N.S. Hahn (eds.) A Planície de inundação do Alto Rio Paraná - aspectos físicos, biológicos e socioeconômicos, Editora da Universidade Estadual de Maringá, p. 47-72.

Thomaz, M.F. \& Thorp, M.B. 1995. Geomorphic response to rapid climatic and hydrologic change durinfg the late Pleistocene and early Holocene in the humid and sub-humid tropics. Quaternary Science Review, 14(2):193-207.

Van der Hammen, T. 1991. Paleoecology of the neotropcs: an overview of the state affair. In: K. Suguio \& M. Tessler (eds.) Proceedings of the Global Changes in South America during the Quaternary, Boletim IG-USP, p. 35-55.

Van der Hoek, C. \& Mannand, D.G. 1995. Algae. An introduction to Phycology. Cambridge, Cambridge University Press, 623 p.

Van Geel, B. 1976. Fossil spores of Zygnemataceae in ditches of a prehistoric settlement in Hoogkarspel (The Netherlands). Review of Palaeobotany and Palynology, 22:337-344.

Van Geel, B. 1978. A palaeoecological study of Holocene peat bog sections in Germany and the Netherlaands, based on one analysis of pollen and macro- and microscopic remains of fungi, algae, cormophytes and animals. Review of Palaeobotany and Palynology, 25:1-120.

Van Gell, B. \& Van der Hammem, T. 1978. Zygnemataceae in Quaternary, Colombian sediments. Review of Palaeobotany and Palynology, 25(5):377-392

Received in January, 2006; accepted in March, 2006 